\title{
Concrete mixture grout for printing extruder
}

\author{
E. Grigoryan ${ }^{1}, A$. Babanina ${ }^{1}$, Andrey Eropkin ${ }^{2}$ \\ ${ }^{1}$ Peter the Great St. Petersburg Polytechnic University, Polytechnicheskaya street, 29, Saint \\ Petersburg, 195251, Russia \\ ${ }^{2}$ Moscow Aviation Institute, Volokolamskoe highway, 4, Moscow, 125993, Russia
}

\begin{abstract}
The method of full or partial automation of masonry of stone structures has great prospects. A big hindrance to the development of 3D technology in construction is the need to adapt the concrete mixture to the narrow aperture of the nozzle of the extrusion die. In additive manufacturing, known as $3 \mathrm{D}$ printing, properties such as the static and dynamic yield stresses of jointing materials play a main role. The purpose of this article is to define the most optimal concrete mix solution for a printing extruder, which will have the highest rheological indices. In the article was considered the scheme of solution feeding system. The optimum percentage relationship of raw materials included in the watercement solution for further feeding through the nozzle was calculated. The static yield strength of the concrete mixture exceeds $5000 \mathrm{~Pa}$, and the dynamic - above $250 \mathrm{~Pa}$.
\end{abstract}

\section{Introduction}

Today a large number of studies are carried out to study the automation of the construction process, including the introduction of a $3 \mathrm{D}$ construction printer. Nevertheless, despite the rapid pace of increasing labor productivity, the construction industry lags behind other areas in which automation technologies have been introduced. Other industrial spheres, such as the automotive industry, have fully undergone changes in the values of improving product quality and productivity with the advent of new 3D technologies [1]. The method of full or partial automation of masonry of stone structures has the ability to remotely update and modify, so this system has prospects for further research.

Digital BIM-design tools are already quite well developed and people have more and more necessities to use it, while automated manufacturing methods still ca not used in practice and need to be researched. Awareness of the fact of the promising use of such technology has led to an increase in numbers of carried out researches in this area in recent years [2-4]. The main problem of printing structures using selective layer-by-layer extrusion deposition is low mobility and poor weather resistance of printing equipment [56]. The disadvantages mentioned above are applicable to mass construction at construction sites. At the present moment, printing of structural components takes place in spacious and equipped rooms, and after that the element is transported to the construction site. This automation method is not optimal, it is also complex and most of the times is economically 
unprofitable for developers regarding to the trivial forms of the building. The issue of mobilizing a construction $3 \mathrm{D}$ printer remains relevant to this day.

The majority of the previously known and proposed approaches to the creation of additive concretes based on extrusion cannot meet the requirements of large-scale mass construction, moreover, with an increase of the dimensions of structural or non-structural components, the expenditure of machines increases accordingly. Therefore, the big hindrance to the development of $3 \mathrm{D}$ technology in construction is the need to adapt the concrete mixture to the narrow aperture of the nozzle of the extrusion die. In addition, it should be noted that construction with concrete printing can increase the cost of materials, since in practical implementation the need for a concrete mixture of a higher and more expensive class relative to traditional mixtures will increase.

In additive manufacturing, known as $3 \mathrm{D}$ printing, properties such as the static and dynamic yield stresses of jointing materials play a main role. In this process, it is very important to apply the solution layer by layer without having any noticeable deformation of the lower layers. Moreover, the yield strengths must comply with international standards that will allow working with this material in real conditions. A lot of researches by different authors led to the that there were identified some components, which affect the static and dynamic fluidity, such as the percentage of water in solution, the addition of various impurities, and others [7-9].

According to opinion of Liu Z. and other authors, jointing materials used in 3D printing consist of five groups of combinations:

- Portland cement (with 12-16\% volume fraction)

- Silica fume (21-26\%)

- Sifting sand (25-30\%)

- Furnace dust (33-35\%)

- Water (2-4\%)

The purpose of this article is to define the most optimal concrete mix solution for a printing extruder, which will have the highest rheological indices. To achieve this goal, there were set the following tasks:

1) Consider the scheme of the solution feeding system, which will be able to be strengthened on the "arm" of the articulated robot-manipulator, as well as dosage in the field.

2) Identify the exact dynamic and static limits of the concrete grout, which will be most optimal for feeding through the print die.

3) Calculate the optimum percentage relationship of raw materials included in the water-cement solution for further feeding through the nozzle.

\section{Materials and methods}

\subsection{The device that was used for testing the method of solution`s feeding}

During the research, the Mitsubishi RV-2AJ articulated robot equipped with position sensors and pneumatic grips was used as a manipulator (Fig. 1). Ceramic solid bricks with a scale of 1:10 relative to the dimensions of a conventional full-size brick and a special gypsum-based grout with an average solidification rate, which by its properties in its experience replaced the water-cement grout, were chosen as building materials. The ultimate goal of this experiment was to build a masonry, similar to the real one, without using hands. The column, according to preliminary data, had to withstand a maximum load, approximately equal to that which a column made of the same material could withstand if it 
was created by man. It was built 3 columns by manipulator and 5 pillars, built by hand. The tests were carried out on central compression with fixing the ultimate load.

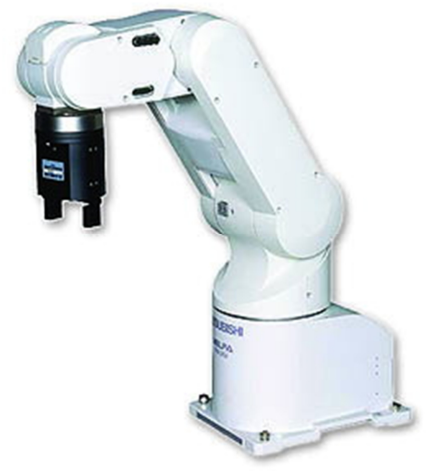

Fig. 1. Mitsubishi RV-2AJ

The initial stage of the test is the connection of this manipulator to the computer and its control with the programming language MELFABASICIV. The manipulator itself has not been created for construction work, this model of the robot was designed for work related to the conveyor feed of material, therefore many functions of its language are suitable for working with building materials, as well as there is required number of optical sensors, so this device can be used in quality of theoretical calculations for the necessary experiments and studies. It is worth saying that the manipulator has the same error both working with miniature nozzles and tools, and with real ones, unlike human hands (Fig. 2).

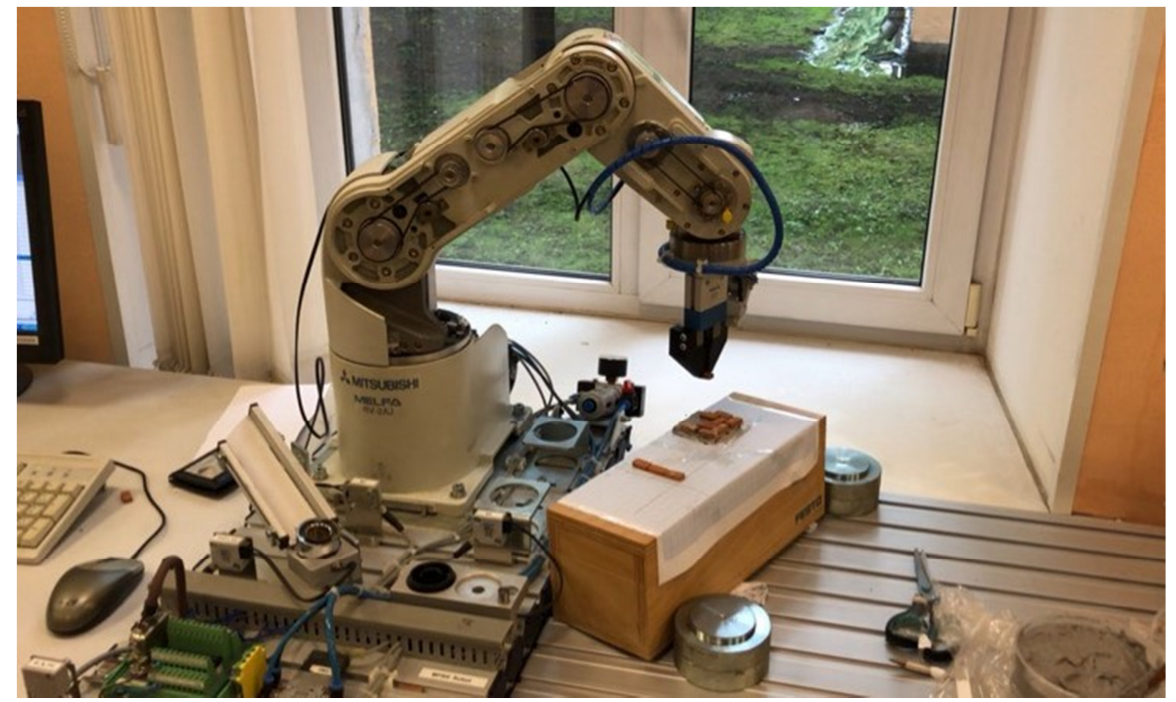

Fig. 2. Working with the manipulator

The second stage of the work was to fix the correct position of the coordinate axe for more convenient operation using the position sensor installed in the robot. The position of the axes was chosen in such a way in which the nozzle on the manipulator had the ability to move within its limits (Fig. 3.), moreover, the walls in the future overlay should be located along one of the horizontal axes, since the movement of the extruder in "inconvenient" directions is less accurate due to the inclusion of more elements of the robot. It was also 
noted that the trajectory of the movement of such a manipulator increases inaccuracy with an increase of the radius of work.

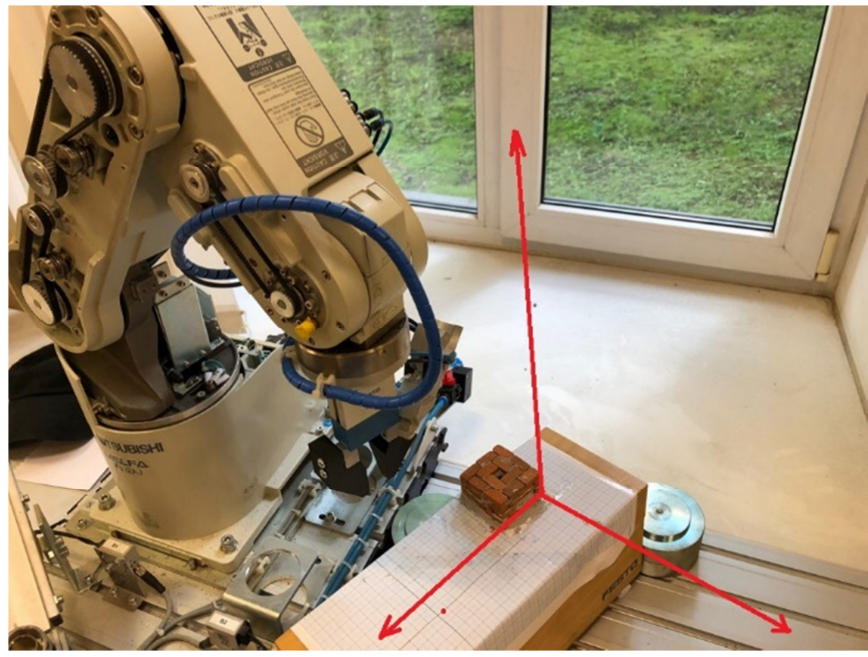

Fig. 3. Position of coordinate axes for solution feeding

The next step is to set the source, finished coordinates and the trajectory of the extruder in each process. Considering that the starting position is the same (the solution is fed using a conveyor feed), the future cycle of actions will be limited to the value of the starting point with a different level of height. The final levels of each layer are different, therefore, for each layer there was chosen and recorded its own position. Later, taking into account its size, the extruder was smoothly moving to the starting position of the new layer (rose on a certain distance).

The last step is writing a program which allows the manipulator to move from one position to another (the MOV command), squeeze and unclenche the tongs of the tongs (HOPEN 1 and HCLOSE 1), the translational energy of which subsequently passed into the rotational energy of the screw, set a certain percentage of the maximum speed (OVRD 10) and paused between movements depending on their need (DLY 1). After writing each command, you need to make sure in the accuracy of the construction of the first layer, set the cycle command of the same actions with an upward shift.

\subsection{Device for concrete feeding}

The main components of the solution feeding system are shown in Figure 4. 


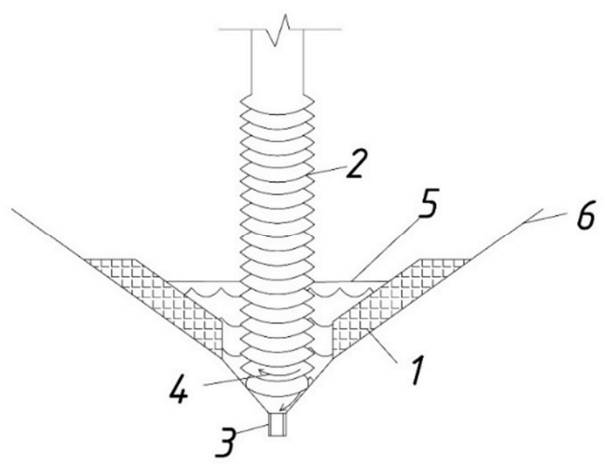

Fig. 4. Extruder of printing device

Elements of the presented device:

1. Heat insulator;

2. Rotational screw with a certain thread pitch;

3. Extruder nozzle;

4. The direction of rotation of the screw;

5. The level of water-cement grout;

6. The body of the extruder.

The concrete mixture is supplied through the nozzle in this system by rotating the screw with a certain thread pitch (2), during which the liquid fills the empty space between the threads and, during rotation, goes down through the nozzle (3).

Mounting to the grips of the manipulator is designed depending on their size and shape. The main objective is the transfer of translational energy into rotational energy using a crank mechanism. For a better view, on the Figure 5 was shown a diagram of the fastening to the Mitsubishi RV-2AJ articulated arm.

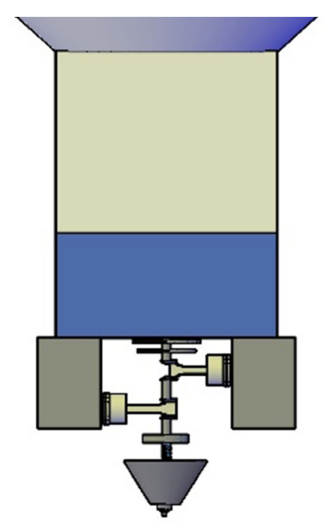

Fig. 5. The scheme of fastening the extruder to the manipulator

\subsection{Concrete rheology}

To determine the static and dynamic fluid limits (rheology), it should be noted that fresh concrete immediately after supply, before its segregation is considered as a liquid. This suggests that with this method of consideration, it is not the motion of most solid particles that is taken into account, but individual particles. Moreover, considering concrete as a liquid, it can be assumed that the shear stress $\tau$ is linearly proportional to the shear rate $\gamma$. 
This dependence will manifest itself until certain yield strength is reached (Bingham yield strength):

$$
G * \gamma=\tau ; \tau \leq \tau_{0}
$$

$\mathrm{G}$ is the concrete shear modulus (according to Russian state standard SP 41.13330.2012, the shear modulus $G$ should be taken equal to $0,4 * E_{b}$ ), which depends on the concrete class in terms of compressive strength.

After overcoming the yield strength $\tau_{0}$, the solution begins to manifest itself dilatantly (the mixture begins to self-compact). Then the formula for the dependence of shear stress on speed takes the following form:

$$
\tau_{0}+\mu \cdot \gamma^{\prime \prime}=\tau ; \tau \geq \tau_{0}
$$

$\mu$ is the plastic viscosity of the fluid.

ConTec Visco5 allows you to calculate the optimal ratio of concrete components. Considering that the temperature and the rotation speed of the installation probe influence the rheology of the mixture to a greater extent, we can express a certain dependence and calculate the optimal ratio of the components of the mixture by repeating the same mixing process at different percentages and external factors. The selection of a more optimal ratio of components can be brought closer to ideal by conducting this experiment a large number of times, but in this article the number of experiments and calculations carried out will be limited to fifteen attempts. The volume of each sample was 31 . The mixing sequence was performed as follows:

1. Mixing of dry components at the same speed $\mathrm{V}_{1}$ for 3 minutes;

2. Water is added to the mixture. The duration of its mixing is 1 minute at a different rotation speed $\mathrm{V}_{2}$. This procedure changes the speed 2 more times, with each minute the speed increases (first $\mathrm{V}_{3}$, later $\mathrm{V}_{4}$ );

3. Fresh material is mixed for 3 minutes at a speed of $V_{3}$.

During rotation, the mixture was pre-cut for 3 minutes. The rotation speed gradually increased from $10 \mathrm{rpm}$ to 80 , and later decreased with the same acceleration. The cut material was calculated on the basis of the dynamic yield strength based on studies [10]:

$$
T=\frac{4 \pi h \ln \left(\frac{R_{0}}{R_{i}}\right)}{\left(\frac{1}{R_{i}^{2}}-\frac{1}{R_{0}^{2}}\right)} \cdot \tau_{0}+\frac{2 \pi^{2} h}{15 \cdot\left(\frac{1}{R_{i}^{2}}-\frac{1}{R_{0}^{2}}\right)} k \cdot N
$$

Where $\mathrm{h}$ is the height of the inner cylinder, $\mathrm{R}_{0}$ is the inner radius of the outer cylinder (in this device $=0.145 \mathrm{~m}), \mathrm{R}_{\mathrm{i}}$ is the outer radius of the inner cylinder $(=0.100 \mathrm{~m}), \mathrm{k}$ is the consistency coefficient, $\mathrm{N}$ is the angular velocity of the outer cylinder.

Figure 6 shows a device capable of stirring a mixture to determine the static and dynamic fluid limits. 


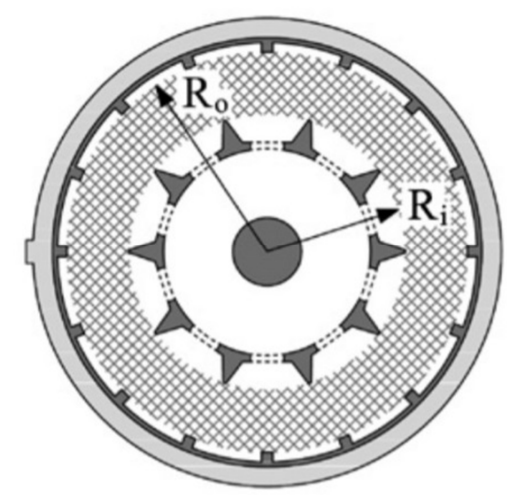

Fig. 6. Diagrammatic representation of a device that determines the rheological properties of the solution (bottom view)

\section{Results and discussion}

Using all of the above dependencies, 15 different experiments were carried out with different percentages of each component in a water-cement mortar to select the most optimal ratio suitable for the proposed solution feeding device. All percentages are presented in table 1. It should be clarified that in total all components should be equal to $100 \%$ (Table 1 ).

Table 1. Percentage of components in 15 different cases

\begin{tabular}{|c|c|c|c|c|c|}
\hline No & Cement (\%) & Sand (\%) & Fly ash (\%) & Water (\%) & $\begin{array}{c}\text { Silica fume } \\
(\%)\end{array}$ \\
\hline 1 & 16 & 21 & 28 & 33 & 2 \\
\hline 2 & 12 & 23 & 30 & 33 & 2 \\
\hline 3 & 12 & 21 & 30 & 35 & 2 \\
\hline 4 & 12 & 24 & 25 & 35 & 4 \\
\hline 5 & 12 & 21 & 28 & 35 & 4 \\
\hline 6 & 16 & 26 & 26 & 35 & 2 \\
\hline 7 & 14 & 22,6 & 26,6 & 33,9 & 2,9 \\
\hline 8 & 16 & 24 & 25 & 33 & 2 \\
\hline 9 & 16 & 21 & 25 & 34 & 4 \\
\hline 10 & 14 & 21 & 30 & 33 & 2 \\
\hline 11 & 12 & 26 & 25 & 35 & 2 \\
\hline 12 & 16 & 21 & 26 & 33 & 4 \\
\hline 13 & 12 & 26 & 25 & 33 & 4 \\
\hline 14 & 16 & 22 & 25 & 33 & 4 \\
\hline 15 & 16 & 21 & 25 & 35 & 3 \\
\hline
\end{tabular}

After the selected compositions, the rheological properties of the materials were calculated. First, the yield stress $\tau$ was found from formulas (1) and (2). Later, using the well-known dependence of these quantities, the values of $\tau_{0}$ were determined (Table 2 ). 
Table 2. Rheological properties of cement material

\begin{tabular}{|c|c|c|c|}
\hline No & Material & Static yield stress, $\tau(\mathrm{Pa})$ & Dynamic yield stress, $\tau_{0}(\mathrm{~Pa})$ \\
\hline 1 & M1 & 2360,14 & 244,80 \\
\hline 2 & M2 & 915,81 & 150,16 \\
\hline 3 & M3 & 541,10 & 70,65 \\
\hline 4 & M4 & 570,90 & 124,40 \\
\hline 5 & M5 & 992,96 & 150,97 \\
\hline 6 & M6 & 682,81 & 98,26 \\
\hline 7 & M7 & 1197,37 & 220,26 \\
\hline 8 & M8 & 1356,40 & 190,22 \\
\hline 9 & M9 & 3050,11 & 321,13 \\
\hline 10 & M10 & 573,01 & 260,14 \\
\hline 11 & M11 & 970,16 & 127,55 \\
\hline 12 & M12 & 5990,21 & 248,48 \\
\hline 13 & M13 & 1695,57 & 209,71 \\
\hline 14 & M14 & 5390,04 & 274,12 \\
\hline 15 & M15 & 961,69 & 154,09 \\
\hline
\end{tabular}

The results of measurements are presented in chart form for more accurate understanding and clarity (Fig.7).

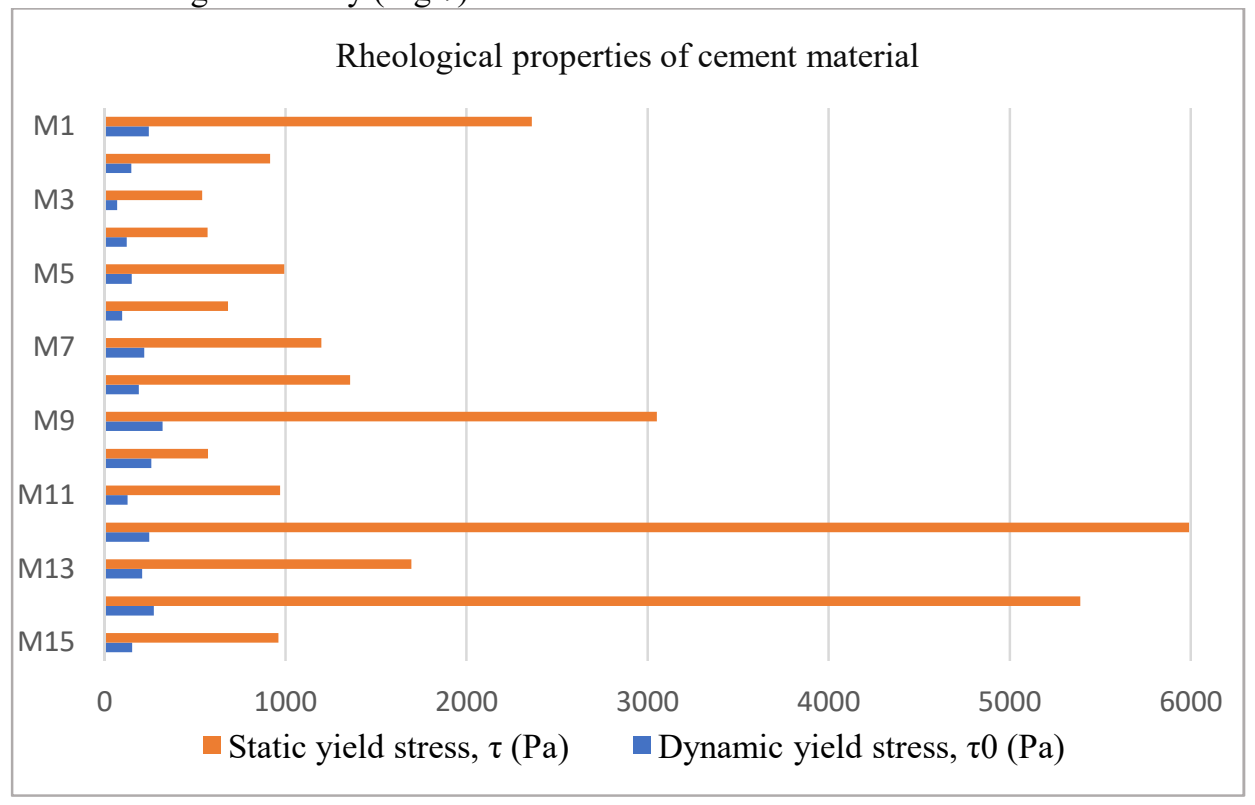

Fig. 7. Rheological properties of the cement material

As it is seen from the diagram, a higher water content leads to a decrease in both the static and dynamic indices. Among all the given ratios of rheological properties, the highest values of the static yield stress are in experiments No. 12 and No. 14. Higher values of the dynamic yield stress are recorded in experiments No. 9 and No. 14. Judging by the studies, the most optimal material that has the highest rheological indicators is material M14. 


\section{Conclusion}

There was carried out a research to detect the influence of the percentage of the system consisting of sand, cement and fly ash on the static and dynamic yield stresses. Based on 15 experiments with a different percentage of solution components, there was selected the most optimal composition, which contains $16 \%$ cement, $22 \%$ sand, $25 \%$ fly ash, $33 \%$ water and $4 \%$ silica powder. In this case, the static yield strength will be higher than $5000 \mathrm{~Pa}$, and the dynamic - more than $250 \mathrm{~Pa}$, which will allow the fresh solution to withstand the load of the subsequent applied layers. Therefore, theoretically, this system can be used in real conditions.

All stages of working with the robot, which correspond to the control of a construction robot manipulator with pneumatic grippers, were also shown. The practical use of the articulated robotic arm in brickwork is quite feasible. But there are still two problems:

- the mobility of the manipulator and the aspect ratio should differ from those used in this study. The full-size extruder has a scale that is 10 times larger than the layout, it means that commensurate manipulator will be of unacceptable size;

- the use of a traditional water-cement grout for applying layers is impossible for many reasons, therefore, as a solution, it is necessary to use better materials with certain properties and characteristics.

\section{References}

1. Dalenogare, L.S., Benitez, G.B., Ayala, N.F., Frank, A.G.: The expected contribution of Industry 4.0 technologies for industrial performance. Int. J. Prod. Econ. 204, 383-394 (2018).

2. Wangler, T., Lloret, E., Reiter, L., Hack, N., Gramazio, F., Kohler, M., Bernhard, M., Dillenburger, B.: Digital concrete: opportunities and challenges. RILEM Tech. Lett. 1, 67-75 (2016).

3. Wu Wang, J., Wang, X.: A critical review of the use of 3-D printing in the construction industry. Autom. Constr. 68, 21-31 (2016).

4. Nerella, V.N., Hempel, S., Mechtcherine, V.: Effects of layer-interface properties on mechanical performance of concrete elements produced by extrusion-based 3D-printing. Constr. Build. Mater. 205, 586-601 (2019).

5. Khoshnevis, B.: Automated construction by contour crafting - related robotics and information technologies. Autom. Constr. 13, 5-19 (2004).

6. Buswell, R.A., Soar, R.C., Gibb, A.G.F., Thorpe, A.: Freeform construction: mega-scale rapid manufacturing for construction. Autom. Constr. 16, 224-231 (2007).

7. Paul, S.C., Tay, Y.W.D., Panda, B., Tan, M.J.: Fresh and hardened properties of 3D printable cementitious materials for building and construction. Arch. Civ. Mech. Eng. 18 (1), 311-319 (2018).

8. $\quad$ Paul, S.C., Tay, Y.W.D., Panda, B., Noor Mohamed, N.A., Tan, M.J., Leong, K.F.: 3D printing trends in building and construction industry: a review. Virtual Phys. Prototyping 12 (3), 261276 (2017).

9. $\mathrm{Hu}, \mathrm{J}$. , Wang, K.: Effects of size and uncompacted voids of aggregate on mortar flow ability. J. Adv. Concr. Technol. 5 (1), 75-85 (2007).

10. Heirman, G., Vandewalle, L., Van Gemert, D., Wallevik, Ó. Integration approach of the Couette inverse problem of powder type self-compacting concrete in a wide-gap concentric cylinder rheometer. Journal of Non-Newtonian Fluid Mechanics 150 (2-3), 93-103 (2008). 